\title{
The Preventive Detention of "Dangerous" Sex Offenders in Australia: Perspectives at the Coalface
}

\author{
Patrick Keyzer ${ }^{1}$ and Bernadette McSherry ${ }^{2 *}$ \\ ${ }^{1}$ Centre for Law, Governance and Public Policy, Bond University, Gold Coast, QLD, 4229, Australia \\ ${ }^{2}$ Melbourne Social Equity Institute, University of Melbourne, Parkville, VIC 3010, Australia
}

\begin{abstract}
Four Australian states, Queensland, New South Wales, Western Australia and Victoria as well as the Northern Territory have enacted laws that enable the continued detention in prison of "dangerous" sex offenders beyond the completion of their sentence. This has proved to be a popular response from a political and social policy perspective, with the New South Wales government recently extending its scheme to include serious violent offenders. While the Queensland scheme has been upheld by the High Court of Australia as constitutional, preventive detention laws raise human rights issues and problems with implementation. This paper outlines the results of 86 interviews carried out with psychiatrists, psychologists, social workers, former corrective services officials, lawyers and police officers who have firsthand experience with the operation of the Australian schemes. The results indicate that those at the "coalface" in relation to post-sentence preventive detention schemes are critical of a number of matters such as the general reliance on preventive detention rather than rehabilitation, the reliance on and use of risk assessment tools as well as media reporting of sex offenders.
\end{abstract}

Keywords: Preventive detention, sex offenders, dangerousness.

\section{INTRODUCTION}

On 30 December 2012, Dennis Ferguson was found dead in his Department of Housing apartment in central Sydney. In 2003, he had been released from Brisbane's Wolston prison after serving 14 years for the kidnapping and assault of three young children. The community outrage that followed Ferguson's release led to his being hounded from town to town in both Queensland and New South Wales (McSherry and Keyzer, 2009). It also led to the enactment in Australia of legislation, first in Queensland and then in three other states and the Northern Territory, that enables the continued detention in prison of "dangerous" sex offenders beyond the completion of their sentence (Keyzer, Pereira and Southwood, 2004). Ironically, because he had already been released, Dennis Ferguson was unable to be detained under the Dangerous Prisoners (Sexual Offenders) Act 2003 (Qld). The Australian post-sentence detention schemes differ from those that enable indefinite prison terms at the time of sentence because they come into play just prior to the prisoner's release (Keyzer, 2008). They also differ from United States "sexually violent predator schemes" which enable the civil commitment of offenders with "mental abnormalities" for treatment and control (La Fond 2005, 2011; Janus, 2006) in that the Australian schemes are not tied to any diagnostic criteria.

*Address correspondence to this author at the Melbourne Social Equity Institute, University of Melbourne, Parkville, VIC 3010, Australia;

Tel: 613 90357434; E-mail: bernadette.mcsherry@unimelb.edu.au
Under the Queensland legislation, the first of its type in Australia, the Attorney-General may apply to the state's Supreme Court for a continuing detention order during the last six months of a sex offender's term of imprisonment. Under section 13, the Supreme Court must be satisfied to a high degree of probability that the prisoner is a "serious danger to the community", that is, that there is an "unacceptable risk that the prisoner will commit a serious sexual offence" if released from custody. The court has some discretion: - it can make a "continuing detention order" for indefinite detention or a "supervision order" where the prisoner is released from custody but is subject to certain conditions such as reporting to and receiving visits from a corrective services officer.

Section 3 of the Queensland legislation states that the objects of the Act are:

(a) to provide for the continued detention in custody or supervised release of a particular class of prisoner to ensure adequate protection of the community; and

(b) to provide continuing control, care or treatment of a particular class of prisoner to facilitate their rehabilitation.

The majority of the High Court of Australia in Fardon $v$ Attorney-General (QId) (2004) held that the Queensland Act was constitutional. Similar schemes have subsequently been enacted in other Australian jurisdictions by the Dangerous Sexual Offenders Act 
2006 (WA); the Crimes (Serious Sex Offenders) Act 2006 (NSW); the Serious Sex Offenders (Detention and Supervision) Act 2009 (Vic) and the Serious Sex Offenders Act 2013 (NT). The New South Wales Act has been amended by the Crimes (Serious Sex Offenders) Act 2013 such that it now relates to "high risk sex offenders and high risk violent offenders", but the main features of the scheme remain the same.

While the schemes vary in detail across the states and the Northern Territory (McSherry and Keyzer, 2009), they share the same primary purpose of community protection. For example, section 4 of the Western Australian Act follows the objects section of the Queensland Act set out above, but omits any mention of rehabilitation. Section 3 of the New South Wales Act mentions encouraging serious sex offenders to undertake rehabilitation, but omits any mention of control, care or treatment, focusing instead on "the safety and protection of the community". There are other differences in the language used regarding, for example, the risk of harm (McSherry, 2014), but the main features of these schemes are very similar.

There is a developing literature on the legal and human rights implications of the Australian preventive detention schemes (McSherry and Keyzer 2009; Keyzer, 2009; Keyzer, 2010; McSherry 2012), but little has been written about the perceptions of those "at the coalface" of the operation of such schemes concerning their advantages and disadvantages.

This article analyses the results of 86 interviews conducted as part of an Australian Research Council Discovery Project (DP0877171) entitled Preventive Detention of High Risk Offenders: The Search for Effective and Legitimate Parameters. Eighty-six semistructured interviews were conducted in Queensland, Western Australia and New South Wales over a twoand-a-half year period with psychiatrists, psychologists, social workers, former corrective services officials, lawyers and police officers who have firsthand experience with the operation of the Australian schemes. Because the project was focused on those who work with the schemes, victims or representatives of victim groups were not included in the interviews.

The interviewees were questioned in relation to their attitudes to (1) preventive detention schemes for sex offenders; (2) risk assessment for the purposes of such schemes; and (3) the role of the media in the operation of the schemes. Interviewees were randomly selected from a review of the case reports published by the Australasian Legal Information Institute using a legislation name "note up" function available at that resource. Snowball sampling was then used to ensure coverage of key professional groups and stakeholders (prosecution and defence) along with geographical spread across and within the three State jurisdictions of Queensland, Western Australia and New South Wales.

Table 1 Sets out the number of participants interviewed by role and jurisdiction.

The interviews were entirely voluntary and were conducted on the basis that the identity of the participants would not be revealed in any publications without the prior consent of the participant concerned. The interviews were conducted on a one-to-one basis between the interviewer and participant. All interviews were tape recorded and transcribed by a transcription service. The interviewees were asked to comment on four very general questions:

- What are some of the practical issues that have arisen in implementing the preventive detention and supervision scheme?

- What have been the expectations (hopes and fears) in relation to the preventive and detention

Table 1: Interview Participants

\begin{tabular}{|c|c|c|c|}
\hline Position Title & Queensland & New South Wales & Western Australia \\
\hline \hline Psychologists & 6 & 6 & 8 \\
\hline Lawyers & 9 & 11 & 6 \\
\hline Police and Corrections & 2 & 3 & 4 \\
\hline Social Workers & 2 & 2 & 3 \\
\hline Criminologists & 2 & 1 & 3 \\
\hline Psychiatrists & 2 & 4 & 36 \\
\hline Total & 23 & 27 & \\
\hline
\end{tabular}


and supervision scheme and have they been borne out?

- What are some of the issues relating to assessing the risk of future harm to the community?

- $\quad$ Are there any other specific issues relating to preventive detention and supervision schemes you think should be addressed by the project?

Interviews lasted about an hour to ninety minutes. The main justification for asking such general questions and leaving so much time to answer them was that it would allow the interviewees latitude to identify issues that were important to them, and scope to develop points they wanted to make as they emerged.

The transcripts were analysed using the software package NVivo 9, using classic content analysis, supplemented by key-word-in-context analysis (Leech and Onwuegbuzie, 2011). Categories or themes were not pre-determined, but were allowed to emerge from the interviews in accordance with a "grounded theory" approach (Straus and Corbin, 2008). This approach enables themes to be analysed in the absence of an initial hypothesis, providing a "bottom-up" variant of content analysis. This article is organized around the three of the most commonly-occurring themes that emerged from the NVivo analysis.

\section{ATTITUDES ABOUT PREVENTIVE DETENTION AS A POLICY FOR THE MANAGEMENT OF SEX OFFENDERS}

Many of the interviewees expressed concerns about the policy of detaining sex offenders after the conclusion of their prison sentences. One Queensland lawyer argued that preventive detention is "targeted at people who are deserving of it", but criticised its effectiveness and its inconsistency with human rights principles. These criticisms were echoed by other interviewees.

\section{The Effectiveness of Preventive Detention Schemes}

There is "no firm empirical evidence", one Queensland psychologist observed, that sex offender recidivism rates had increased to any substantial degree that necessitated the introduction of preventive detention legislation. "To a large extent", a New South Wales psychologist stated, preventive detention measures were simply a "populist response to a perceived problem". Concern was expressed by many interviewees about the feasibility of the system in the long term. "If you lock people up for a longer period of time you're naturally going to stop them reoffending," a Queensland psychologist observed, but "you've got to let them out at some point in time".

Preventive detention, one New South Wales lawyer stated, "focuses on the wrong end of prevention", and is a "political or short-term strategy but it's not a longterm solution towards keeping the community safe" because "it targets known offenders and ignores the majority of next offenders or present offenders who aren't known to the system". The same interviewee argued that "if we really want to protect the community, we have to look at where the majority of risk comes from, and it doesn't come from the sentenced offender, it comes from everywhere else". At the root of this problem is the fact that, as one Western Australian psychologist observed, the public misguidedly believes that "all sex offenders are predatory...and they'll continue to offend regardless of any treatment you can offer them, and therefore the only option is containment, preferably behind bars".

Five interviewees thought that preventive detention schemes actually make the risk of sex offending worse for the community. A member of the Western Australian police opined that preventive detention "does nothing to stop offending behaviour" in the community, and believes preventive detention "is philosophically wrong" and "not only does it do nothing to prevent recidivism, it actually increases risk". The reason for this, the officer said, is that members of the community have been given a false impression that they are being protected from sex offenders, thus "leaving the community totally at risk to the majority of offenders, who are family members and known people".

One Queensland psychologist opined that preventive detention actually makes offenders "angrier and nastier when they come out of prison". An offender, observed one Western Australian social worker, may have been imprisoned for a long term and could have been seeking treatment throughout that whole period, but instead only dealt with their offending issues at the last minute. A New South Wales psychiatrist suggested that preventive detention regimes "drive offenders further underground" and encourage them to "be more manipulative and deviant", with the result that if the offender is indefinitely detained, the risk then switches from the community to 
other inmates and the prison staff. "If men lose hope of ever getting out," one New South Wales social worker observed, "that makes them more dangerous" because they "have nothing more to lose".

\section{Human Rights Concerns}

Another major concern raised by a majority of the interviewees was the effect that preventive detention measures have on human rights and justice. Preventive detention, argued one Queensland psychologist, is "getting away from that highly respected and useful value of punishing a person for his crime, then allowing him to go". Rather, preventive detention is, as one Western Australian police officer observed, "punishing a person for crimes they haven't committed". If individuals have completed their sentence, another Western Australian police officer observed, "then prima facie they shouldn't be in prison". However, if they are going to be detained, the officer observed, "it seems that the only appropriate way to do so is in something that is not a prison".

If an individual is preventively detained in a prison, one Queensland criminologist observed, "then you would assume that...it would come with endless resources". However, this is not the case. One Queensland Legal Aid lawyer noted that "detention is meant to be...for "care, control and treatment". However, the same interviewee also noted that, "care" and "treatment" are "nonexistent" on preventive detention orders because the offenders are "just treated as mainstream prisoners". Overall, a Queensland psychiatrist observed, preventive detention is "unethical" and "unfair" because it is a "gross infringement on the human rights of individuals who have finished their detention" and constitutes "additional punishment". A Western Australian lawyer observed that "the very high human rights costs of the legislation" is being implemented "without appropriate rational scrutiny".

Eleven interviewees opined that there are more respectful, economical and effective ways to prevent recidivism than preventive detention, including extended supervision orders, monitoring and treatment. One New South Wales barrister argued that preventive detention is simply a short-term, "stepping-stone" measure:

In the short-term you may have to lock people up...but over the medium or longer term you'd like to see interventions - therapeutic, medical or otherwise - to genuinely help these people reintegrate into the community and minimise their risk.

A Queensland lawyer proposed the concept of placing high-risk offenders on a farm where they would be able "to start some sort of meaningful employment and get them away from the general criminal population". Such a facility would convert "detention into supervision in a gradual way".

Overall, a key theme for the interviewees was, as a lawyer from Western Australia observed, balancing the "tension between serving one's 'debt' to the community and the right of the community to be protected".

\section{ATTITUDES TO RISK ASSESSMENT}

While there are slight differences in the Australian legislation concerning the standard of proof in relation to risk (McSherry, 2014), the Australian preventive detention schemes all require evidence of an "unacceptable risk" of re-offending. Expert evidence from psychiatrists is required in this regard. This emphasis on risk raised a number of concerns amongst interviewees including the use of risk assessment tools, the quality of expert evidence and the trend towards over-estimating risk. Some potential solutions to these concerns were also proferred.

\section{The Use of Risk Assessment Tools}

There is a range of different psychometric tests that are employed to assist in the assessment of sex offenders, with the most commonly noted ones throughout the interviews being the Static-99 (Hanson and Thornton, 1999) and the Risk of Sexual Violence Protocol (RSVP) (Hart et al., 2003). The Static-99 is intended to be used on adult sex offenders and consists of ten items dealing with "static" variables such as age, persistence of sexual offending, "deviant" sexual interests, relationship to victims and general criminality. The Static-2002 (Hanson and Thornton, 2003 ) is an updated version that retains the Static-99 risk factors except for the item "never lived with a lover for two years" (which was found to be hard to confirm in practice) and adds several new items. The Risk of Sexual Violence Protocol includes dynamic as well as static factors to assess the risk of sexual violence.

One New South Wales psychologist noted that the current tools are actually designed to manage released offenders in the community rather than provide risk predictions for court purposes, and accordingly are "not 
very useful in predicting the risk of reoffending". A Queensland psychiatrist stated that while tools such as the Static-99 show "that there are factors highly correlated with reoffending in terms of a group and you can quite accurately predict whether someone is in a high risk group", that does not "necessarily translate to accurately predicting whether the individual will reoffend". The Static-99, stated this interviewee, assigns offenders into high, medium or low risk reoffending groups. However, such categorisations are based on a static test and accordingly, an offender will always remain in a given category regardless of individual changes in circumstance. This interviewee noted an example where "you could be catastrophically injured and your physical capacity to reoffend may be completely removed but you'll still rate as a high risk sex offender" according to the risk assessment instruments. This authority also stated that individuals may "have changed and yet are subject to preventative detention or serious controls upon their behaviour upon release from jail, when in fact they didn't present a risk".

The key, observed a Western Australian psychiatrist, is building into the risk assessment process dynamic information about the offender which could "possibly enhance the accuracy of risk measurement". A New South Wales psychologist noted that risk assessment reports could be more specific and that information being provided by the Static-99 is being wasted. While the Static-99 categorises an offender into various risk tiers, it is also able to show how much more likely that offender is to reoffend as compared to another offender. An example of this would be circumstances where the application of a tool indicates that an offender is "four times more likely to reoffend than the average offender". However, according to this interviewee, this useful information is not being used in risk assessment reports.

Timing and time constraints were also raised as an important issue with regard to ensuring the accuracy of risk assessments. With regard to timing, a Western Australian corrections official said that corrections departments should be conducting risk assessments on individuals "from day one instead of waiting until the day of release". The fact that offenders are only assessed just before release, a Queensland lawyer observed, is a "major risk management...and ethical problem". A New South Wales lawyer observed that Corrections Departments are "spending large amounts of money on these assessments at the end of their sentences when they should be doing it at the start".
With regard to time constraints, this interviewee noted that with the introduction of preventive detention legislation, "things had to be done very quickly... rather than having a leisurely year or so to do the proper assessment". For this reason, mental health professionals may not have "adequate time to do proper assessments".

The accuracy and fairness of risk assessments, stated one Queensland lawyer, is compromised by the fact that bias is "inherent" in the risk assessment tools. The tools, another Queensland lawyer observed, look at the long-term relationships and potential for stable employment of an offender outside of prison, and find that they do not exist, which increases the offender's risk rating. However, the reason that they do not exist is partly because the offender has been in prison. Risk, stated one Western Australian lawyer, is "created by the system", which "does not prepare prisoners for release".

The current risk assessment tools have faced particular criticism with regard to their application to indigenous offenders. A Western Australian psychiatrist noted that risk assessment tools have not been "normed in an indigenous population", and a Queensland lawyer highlighted that despite the tools having "very little application" to Indigenous offenders, they are nevertheless "still applied".

In the words of one Queensland psychiatrist, current risk assessment tools and procedures are "notoriously unreliable". A New South Wales psychiatrist expressed concern that inaccuracy in risk assessment can not only lead to the continued detention or supervision of offenders who do not necessarily present a risk to society, but it can also provide the community with "a false sense of security that high risk offenders are being managed". Most of the psychologists and psychiatrists interviewed noted that inaccuracy is caused by a wide range of different factors, including: elasticity of definitions, the diverse skills and experience of assessors, the variable reading of assessment tools, assessment timing, assessor bias and the fact that many tests have not been normed on Australian or Australian indigenous populations.

A major issue concerning risk assessment, one Western Australian psychologist observed, is the "very specific nature of the legislation in exactly how risk is defined". According to this Western Australian psychologist, the term "unacceptable risk" presents problems due to its highly subjective and "arbitrary" 
nature. Another Western Australian psychologist stated that "[i]t is very hard to establish what is an unacceptable level of risk, especially when you look at the risk assessment tools that are used [which] can vary so widely". This interviewee questioned "whether the psychiatrists that are producing the reports understand the very specific nature of the legislation" and what is meant by the terms used.

\section{The Quality of Expert Evidence}

Another major concern noted throughout the interviews regarding risk assessment was the identity and the qualifications of the assessors themselves. There is significant debate regarding whether psychiatrists, as opposed to psychologists, are not only necessary but also effective as risk assessors, and whether this has an effect on assessment accuracy. Risk assessment is much more a feature of forensic psychology than it is a feature of forensic psychiatry, with the result that psychiatrists were perceived to be giving expert evidence that was arguably extraneous to their expertise.

One Queensland psychologist stated that regardless of whether psychologists, psychiatrists or parole officers assess risk, "you still get what I think are unacceptably high rates of false positives and false negatives". There is a "greatly misplaced confidence" in the ability of experts to assess risk, because experts are in fact "not very good at actually predicting the future". Despite being "better than we were twenty or thirty years ago," stated one forensic psychiatrist, "we're still capable of making lots of errors". In addition, a New South Wales psychologist argued that "people who provide treatment are the worst predictors of recidivism because they have a vested interest". Accordingly, this interviewee argued, there needs to be "integrity in the decision-making process about assessing risk".

Particular concerns were expressed about the impartiality of psychologists employed by corrective services departments. One Queensland psychologist gave an anecdote about visiting a jail and being told by a psychologist employed by corrections that a particular offender was considered to be a high risk to the community because he would not participate in a sex offender treatment programme. During each parole hearing for this offender, the corrections psychologist would write a report stating that the offender was a high risk and therefore should not be granted parole.
However, the independent psychologist had discovered that the offender had not been asked whether he would like to participate in a treatment programme for many years. After only a brief interview with the independent psychologist, the offender agreed to treatment. This was "abuse" the psychologist argued.

One New South Wales social worker observed that new risk assessment systems were needed that "have no agenda with...Corrective Services". A number of interviewees (three from each of New South Wales and Queensland and five from Western Australia) called for the appointment of an independent panel of psychiatrists appointed under the regimes, with limited terms, to ensure that assessments were independent and impartial. There should also be, in the words of one Queensland psychologist, a "periodic chucking out" of psychiatrists to avoid the risk that expert witnesses would become captive to Crown submissions that invariably favoured detention or strictly-controlled supervision.

Another issue raised by three interviewees in each of the three States was the lack of forensically qualified psychologists in State prisons and in the supervision apparatus. In the opinion of these interviewees, the lack of expertise available to supervisees yielded an increased risk that people would breach their orders and return to custody.

\section{Over-Estimating Risk}

Another issue raised regarding assessors was that of their motives for over-estimating risk. "Risk management", remarked one Queensland lawyer, has become a matter of "how do you protect the system from criticism for being negligent in their duties to the community". Another Queensland lawyer noted that there is "an underlying fear at all levels of the process that 'I don't want my signature on the one that gets released and...does something very nasty"'. Yet another Queensland lawyer argued that the results of certain risk assessments are often totally predictable because the assessor will look only at the "on-paper" risk of an offender and provide an assessment that limits the assessor's liability. "It is very difficult to truly believe," stated this interviewee, "that an opinion is honestly given, rather than the expectation that they will ensure this person who reads very dangerously on paper stays in custody". A New South Wales lawyer remarked that over-estimating risk presents human rights issues and is "an area for the future that needs to be worked on". 


\section{Potential Solutions}

Many potential solutions were recommended by the interviewees regarding the sex offender risk assessment process. A New South Wales psychologist recommended the formation of an independent body to oversee the risk assessment process. A Queensland psychologist recommended the formation of a federal task force comprised of professionals in the sex offender treatment field from all different states to develop proper risk assessment tools. Ultimately, a Queensland criminologist suggested, risk assessment experts need to be provided with more funding and the process be subject to further research in order to develop a better and more accurate approach.

\section{ATTITUDES TO THE MEDIA}

The media publicity concerning the sex offender, Dennis Ferguson in the years after his release was unrelenting, so much so that the Australian Broadcasting Corporation's television show Media Watch ran a piece about Ferguson's "demonisation" via the media (Media Watch, 2008). Such publicity plays in to the public perception that the "typical" sex offender is a man with limited social skills waiting to prey on the young. However, the research in the field indicates that most sex offenders are known to their victims, most do not have a psychiatric illness and most are never convicted of their crimes (Gelb, 2007).

Three issues emerged from the interviews about the role of the media in the context of preventive detention schemes: first, the political appeal of appearing "tough" on sex offenders (and the consequences that this has had for sex offender policy in these jurisdictions); secondly, the influence of the media (particularly on politicians, but also on the construction of sex offender management issues); and thirdly, misrepresentation of the issues at stake.

\section{The Appeal of Appearing "Tough" on Sex Offenders}

It is difficult, a Queensland criminologist said, to sell "rehabilitative and helpful responses to politicians when you're talking about sex offenders". One major reason for this is that it pays politically - with both voters and in relation to other politicians - to appear "tough" on sex offenders. "Anything that promotes politicians as being tough on sex offenders," the Queensland criminologist argued, "is probably going to be electorally popular" due to the level of public loathing towards them. However, one Queensland psychologist stated "that is not to say that it is going to be effective or just, in the long term". A lawyer from Western Australia argued that when the Western Australian legislation was introduced, politicians appeared to be more interested in the media impact of introducing preventive detention than the recommendations and information being supplied to them about resources and the effectiveness of the regime. The same interviewee said $s / h e$ "expected it [the preventive detention regime] to fail from the beginning" and in this regard "hadn't been disappointed".

A New South Wales lawyer argued that the courts have become sceptical of the preventive detention regimes, and after the failed constitutional challenge, which some regarded as "very surprising", it was perceived that the judges making preventive detention orders regarded themselves as "rubber-stamps" and "political pawns". A Queensland police officer opined that "there is nothing wrong with erring on the conservative side" when it comes to public policy with regard to sex offenders, as long as the motive behind such an approach is "protecting the community" rather than "protecting one's own reputation". A New South Wales psychiatrist concluded that it is difficult to know the extent to which preventive detention regimes are "being used for political reasons rather than genuine safety issues", and this has caused a "fair degree of unease".

\section{The Influence of the Media}

The media has a powerful role in shaping opinions regarding sex offending. Unfortunately, a Queensland lawyer observed, "the application of common sense and human dignity towards others does not catch headlines". Seven interviewees regarded the media to be a negative influence on the development of effective policies in this context. While public policy and legislative changes must be "subjected to fair review and scrutiny in the media", one New South Wales lawyer urged politicians to make informed and independent decisions as opposed to being dictated by the media's interests. One New South Wales psychologist stated that without such independence, politicians were at risk of instigating legislative changes in the form of "knee-jerk reactions to public outcry". One Queensland psychologist observed:

I got the impression that political convenience, especially in relation to pressures from the tabloid media...was playing some role in the whole process which was causing some unease...the 
scheme was being implemented at very high human costs, without appropriate rational scrutiny.

Preventive detention, stated a Western Australian psychologist, "is just a case again of popular punitivism... reacting to public pressure and not having informed views". A Queensland criminologist observed that there was no firm empirical evidence that demonstrated that sex offenders are reoffending more or that sexual offences have increased.

Interestingly, the Courier Mail, a tabloid newspaper based in Brisbane, Queensland, was perceived as a driving force behind political decision-making in fourteen interviews conducted in that State. It was argued that Queensland's preventive detention regime (Australia's first) was "driven by media reports, and especially the Courier Mail, which has enormous sway in the State".

A Queensland psychologist pointed to two dimensions of the influence of the Courier Mail. The first was that the newspaper tended to reflect the opinions of the majority of Queenslanders, who this interviewee regarded to be an "apathetic and conservative electorate which applies a punitive or law and order agenda to crime and criminal issues". The second dimension of the influence of the Courier Mail was that it was the only newspaper in Brisbane: "the Courier Mail in a one newspaper-town," stated this interviewee and "[it] has enormous influence on...politicians of both parties".

Politicians "know that the electorate is conservative", a Queensland lawyer observed, "and...if the Courier Mail says there's a problem or implies there's a problem then...politicians respond accordingly". Ultimately, stated a Queensland psychologist, while it is difficult to find any solid empirical evidence that demonstrates a link between decision-making and the views of the newspaper, politicians are afraid of incurring the "wrath" of the Courier Mail. Other, credible media sources such as the 7.30 Report, a Queensland lawyer observed, only appeal to a small audience. The Courier Mail, on the other hand, is "a very powerful organ".

The media was regarded to play a significant role in propelling unsophisticated responses regarding what to do with post-release sex offenders, such as, in the words of one Queensland psychiatrist, "castrate...or hang the bastard". An underlying cause of this, explained one Queensland lawyer, is that the community simply is not aware of the significant restrictions that are applied to sex offenders when they are released into the community and instead, the community has a naïve perception that "we're just releasing them and letting them go on their merry way".

\section{Media Misrepresentations}

A number of interviewees argued that the media is responsible for misrepresenting the facts to the community at large.

At a basic and a general level, seven interviewees believed that the community, including highly-educated professionals such as lawyers and many politicians, "do not understand sexual abuse". From conservative current affairs programmes to even the allegedly "more up-market" news programmes such as the $A B C$ News, a Western Australian psychologist observed that "offenders....are presented in the stereotypical 'I'm a dangerous sex offender' way". A Western Australian criminologist stated that sex offenders are "seen as being bizarre, like Dennis Ferguson, because they're running around waving their arms at photographers". Such a response by an offender is normal, argued a New South Wales social worker, considering the level of harassment that such released offenders face from the media. "The media," this interviewee explained, "present them as being strange, bizarre people". However, "this is not what most sexual offenders are like, and we're fooling the community if we're trying to tell them how to identify sex offenders". Rather, a Queensland psychologist observed, a large proportion of sex offenders are those who have committed offences such as "incest with stepdaughters, exhibitionism and relationships with girls or boys who are just under the age of consent". These offenders and their respective offences, that interviewee observed, "do not fit the stereotype sex offender", nor do they induce the same emotive response from audiences.

Commercial news and current affairs programmes, explained a Queensland criminologist "take the most atypical case of the most bizarre person and then provoke them to act in an even more bizarre way". Promoting such individuals as the average sex offender is "a very erroneous view". Further, by harassing offenders in the media, this interviewee observed, such as in the case of Dennis Ferguson, "the public are actually behaving in ways that will maximise chances of reoffending" by placing stress on the offender. 
A Western Australian corrections official observed that measures taken by politicians in response to the false depiction of the "average sex offender" - such as preventive detention - do not target the "real average sex offender". Rather, they are short-term, political devices employed to appease an ill-informed public. The majority of sex offenders, a Western Australian psychologist observed, are in fact family members or those known to the victim, as opposed to the classically depicted "stranger" offender. As such, preventive detention "focuses at the wrong end of prevention", targeting already known offenders and ignoring the majority who are not within the system or known to the community. Ultimately, this interviewee observed, the community are given a false sense of security and are left at risk. Further, a New South Wales lawyer stated that preventive detention "does nothing to stop offending behaviour", but "is simply a response to a media-driven fear campaign".

Seven interviewees criticised what was referred to as the misrepresentation of "true risks" by the media. One Queensland Prison Psychologist and a Criminology Professor noted that recidivism rates are probably within the range of approximately 13 percent and, although that rate "does not allow for the fact that some will be re-offending and not being caught, is nevertheless nothing like the 90,95 percent image that is portrayed in the media".

Finally, there was a perception that the media, the community and professionals tend to over-simplify what is essentially an extremely complex issue. "We all want to live in a safe world," said one Queensland psychologist "and we think it's simple... and politicians don't have the time or the inclination to explain the complexity of it". A New South Wales psychiatrist observed that the community does not understand the complexity of or the statistics behind sexual offending and presenting a balanced message to the community is "an uphill battle all the time". In agreement, a Western Australian corrections official believed that politicians treat this "very, very complex issue" with "very, very simple answers" because "that's what the public wants". This interviewee stated that "politicians know in their heart of hearts that it's just icing...just frivolous" and that the administration of post-release transitions will continue to be "thwarted by this mass hysteria", such as in the case of the constant relocation of Dennis Ferguson, "until there's some new kind of 'witch' that they can focus on".

\section{CONCLUSION}

Marijke Malsch and Marius Duker (2012: 5) have pointed out that detaining people in prisons or other institutions "works directly and speedily, which renders it attractive to policy makers". At the coalface, however, many of those involved in the operation of the Australian preventive detention schemes are concerned that they are not the best way of preventing sex offences in the community. Supervision, monitoring and treatment were seen by many interviewees as preferable to continued imprisonment.

A number of concerns were raised by interviewees about the dependence on risk assessment and expert evidence as an integral part of preventive detention schemes. A co-ordinated response to the training and provision of experts on risk may go some way towards alleviating such concerns. Scotland's Risk Management Authority which trains and accredits forensic risk assessors and which rates risk assessment tools, provides an example of such a coordinated response (McSherry and Keyzer, 2009). However, many of those interviewed raised more philosophical concerns with the whole notion of risk as the basis for the deprivation of liberty, particularly because there was a perceived tendency on the part of assessors to over-estimate risk. The ethics of giving risk assessment testimony for the deprivation of liberty is one area that needs further examination.

The role of the media in shaping opinions regarding sex offending and driving public policy in relation to preventive detention schemes was also a key issue raised by interviewees. While many criticised the portrayal of sex offenders in the media, few offered options as to how best to combat the "misrepresentations" of facts. This is obviously an area that requires exploration.

It appears that in Australia, preventive detention schemes will continue to be a popular method of addressing public concerns about sex offenders despite the criticisms outlined by those at the coalface. While the purpose of these schemes is meant to be community protection, it is particularly concerning that so many of the interviewees were of the opinion that they are ineffective and that five interviewees, including a police officer, thought they actually made the situation worse for the community. Perhaps the most that can be hoped for at this stage is that some of the criticisms highlighted will eventually be addressed, but the very fact that those who are in a position to know 
how preventive detention schemes work in practice are critical of their ability to protect the community raises doubts about their merit.

This research was funded by an Australian Research Council Grant, DP0877171, Preventive Detention of High Risk Offenders: The Search for Effective and Legitimate Parameters. The authors thank the busy people who agreed to be interviewed for this research for their time and insights. We also thank Siân Daniel, Philippa Goddard, Nathan Kershler, and particularly Charlotte Deans for their research assistance.

\section{REFERENCES}

Gelb, K. (2007) Recidivism of Sex Offenders: Research Paper. Melbourne: Sentencing Advisory Council.

Hanson, R.K. and Thornton, D. (1999) Static-99: Improving Actuarial Risk Assessments for Sex Offenders: 2000-01. Ottawa: Department of the Solicitor General of Canada.

Hanson, R.K. and Thornton, D. (2003) Notes on the Development of Static-2002: 2003-01. Ottawa: Department of the Solicitor General of Canada http://www.publicsafety.gc.ca/res/cor/rep / fl/2003-01-not-sttc-eng.pdf

Hart, S.D., Kropp, P.R. and Laws, D.R. with Klaver, J., Logan, C., and Watt, K.A. (2003) The Risk for Sexual Violence Protocol (RSVP): Structured Professional Guidelines for Assessing Risk of Sexual Violence. Burnaby, BC: Simon Fraser University Mental Health, Law and Policy Institute.

Keyzer, P. (2010) The United Nations Human Rights Committee's Views about the Legitimate Parameters of the Preventive Detention of Serious Sex Offenders. Criminal Law Journal, 24, 283-291.
Keyzer, P. (2009) The Preventive Detention of Serious Sex Offenders: Further Consideration of the International Human Rights Dimensions. Psychology, Psychiatry and Law, 16(2), 262-270.

http://dx.doi.org/10.1080/13218710802471750

Keyzer, P. (2008) Preserving Due Process or Warehousing the Undesirables? To What End the Separation of Judicial Power of the Commonwealth? Sydney Law Review, 30, 101-114.

Keyzer, P., Pereira, C. and Southwood, S. (2004) Pre-Emptive Imprisonment for Dangerousness. Journal of Psychiatry, Psychology and the Law, 11(2), 244-253. http://dx.doi.org/10.1375/pplt.2004.11.2.244

Leech, N.L. \& Onwuegbuzie, A.J. (2011) Beyond Constant Comparison Qualitative Data Analysis. School Pyschology Quarterly, 25(1), 70-84. http://dx.doi.org/10.1037/a0022711

Malsch, M. \& Duker, M. (2012) Introduction in M. Malsch and M. Duker (eds) Incapacitation: Trends and New Perspectives. Aldershot: Ashgate Publishing Ltd. 1-13.

McSherry, B and Keyzer, P. (2009) Sex Offenders and Preventive Detention: Politics, Policy and Practice. Annandale: The Federation Press.

McSherry, B. (2012) Post-Sentence Incapacitation of Sex Offenders and the Ethics of Risk Assessment in M. Malsch and M. Duker (eds) Incapacitation: Trends and New Perspectives. Aldershot: Ashgate Publishing Ltd. 77-96

McSherry, B. (2014) Managing Fear: The Law and Ethics of Preventive Detention and Risk Assessment. New York: Routledge.

Media Watch (2008) Media Hunt a Monster. Australian Broadcasting Corporation, 14 July, http://www.abc.net.au/mediawatch/ transcripts/s2303501.htm

Straus, A. and Corbin, J. (2008) Basics of Qualitative Research. $3^{\text {rd }}$ edn, Thousand Oaks: Sage.

\section{DOI: http://dx.doi.org/10.6000/1929-4409.2013.02.29}

(C) 2013 Keyzer and McSherry; Licensee Lifescience Global.

This is an open access article licensed under the terms of the Creative Commons Attribution Non-Commercial License (http://creativecommons.org/licenses/by-nc/3.0/) which permits unrestricted, non-commercial use, distribution and reproduction in any medium, provided the work is properly cited. 